\title{
Distribution of arsenic hazard in public water supplies in the United Kingdom - methods, implications for health risks and recommendations
}

\author{
D.A. Polya ${ }^{1}$, L. $\mathrm{Xu}^{1}$, J. Launder ${ }^{1}$, D.C. Gooddy ${ }^{2} \&$ M. Ascott ${ }^{2}$ \\ ${ }^{1}$ School of Earth and Environmental Sciences and Williamson Research Centre for Molecular Environmental Science, \\ University of Manchester, Manchester, UK \\ ${ }^{2}$ Groundwater Science Directorate, British Geological Survey, Wallingford, UK
}

\begin{abstract}
Public water supplies in the United Kingdom are highly regulated and monitored and, in particular, have an outstanding compliance with regulatory standards, particularly with respect to the UK PCV (prescribed concentration value) for arsenic of $10 \mu \mathrm{g} \mathrm{L}^{-1}$. Nevertheless, many UK public water supplies contain arsenic at concentrations within a factor of 10 of the PCV. Given increasing concerns over detrimental health outcomes arising from chronic exposure to drinking water containing arsenic at sub-regulatory concentrations in the $10^{0} \mu \mathrm{g} \mathrm{L}^{-1}$ range, quantifying the distribution of arsenic intake from consumers exposed to arsenic via drinking water in the UK is indicated. Using the limited secondary summary water quality data available in the public domain from the Drinking Water Inspectorate and assuming a log normal distribution, we calculate that, in 2015 , on the order of $10^{5}$ consumers in the UK were supplied with drinking water with arsenic concentrations at or above $5 \mu \mathrm{g} \mathrm{L}^{-1} ; 10^{6}$ at or above $2 \mu \mathrm{g} \mathrm{L}^{-1}$ and $10^{7}$ at or above $1 \mu \mathrm{g} \mathrm{L}^{-1}$. However, examination of much more detailed secondary data kindly supplied by individual UK water supply companies indicates that the overall distribution of arsenic hazard is not log normally distributed and results in an overestimate of the number of the consumers exposed to high As concentrations using that assumption. Our more detailed analysis shows that approximately 130,000 consumers in the UK are supplied with drinking water with arsenic concentrations at or above $5 \mu \mathrm{g} \mathrm{L}^{-1}$; the equivalent figures for other concentrations being $1,080,000$ for at or above $2 \mu \mathrm{g} \mathrm{L}^{-1}$ and $9,750,000$ for at or above $1 \mu \mathrm{g} \mathrm{L}^{-1}$. Epidemiological evidence seems currently insufficiently powerful to reliably quantify the detrimental health outcomes arising from such sub-regulatory exposures, but arsenic-attributable premature avoidable deaths in the UK on the order of 100 to 1000 per annum are plausibly estimated here from combined cancer and cardiovascular disease causes. There are considerable uncertainties in these estimates due to (i) model (e.g. linearity, threshold) and parameter uncertainties in the dose-response relationships at such low concentrations; (ii) partial reliance on ecological studies, which may be sensitive to the nature of adjustment for socio-economic and other potential confounders of risk and (iii) the lack of explicit consideration of the many other sequela for which arsenic is known, at higher concentrations in drinking water, to contribute. We note that, the estimates here, however, are broadly equivalent to the number of annual fatalities of car occupants in road traffic accidents in the UK.
\end{abstract}

\section{INTRODUCTION}

Although arsenic from (mostly) groundwater sourced drinking water supplies is a widely known major global health risk (Polya \& Middleton, 2017; Ravenscroft et al., 2009; Smith et al., 2000) concerns in the UK over arsenic in drinking water supplies have been limited largely to private water supplies, which face less scrutiny than volumetrically more important public water supplies, and which sometimes contain arsenic at concentrations exceeding the WHO provisional guide value of $10 \mu \mathrm{g} \mathrm{L}^{-1}$ (Ander et al., 2016; Crabbe et al., 2017; Middleton et al., 2016). This relatively limited concern has arisen, in part, because public water supplies in the UK are highly regulated and monitored and have outstanding compliance with respect to the UK PCV (prescribed concentration value) for arsenic of $10 \mu \mathrm{g} \mathrm{L}^{-1}$ (DWI, 2016).
Notwithstanding this, many public water supplies in the UK contain arsenic at concentrations within a factor of 10 of the PCV. Given that there are increasing concerns over detrimental health outcomes particularly including premature death from cancers and cardiovascular diseases - arising from chronic exposure to drinking water containing arsenic at subregulatory concentrations in the low $\mu \mathrm{g} \mathrm{L}^{-1}$ range (e.g. Garcia-Esquinas et al., 2013; Medrano et al., 2010; Moon et al., 2017; Pompili et al., 2017; Roh et al., 2017), quantifying the distribution of arsenic intake by UK consumers exposed to arsenic via drinking water from public water supplies is indicated.

Here we report a study, based upon collated secondary data obtained from the DWI (Drinking Water Inspectorate) and other public websites or kindly provided by UK water supply companies, aimed at (i) calculating the distribution of arsenic hazard in UK 
public water supplies; (ii) estimating the resultant human uptake of arsenic; and (iii) obtaining a scoping estimate of plausible human health risks arising from this exposure. Data and model uncertainties are discussed and, in the light of these, research and public policy recommendations made. Finally, we speculate on the potential health implications of exposure in other countries to drinking water with (sub-regulatory) concentrations of arsenic within a factor of 10 of the WHO provisional guide value.

\section{METHODS/EXPERIMENTAL}

\subsection{As hazard distribution - scoping calculation}

DWI (2016) provide summary data, viz. 1st and 99th percentiles of arsenic concentrations, of arsenic concentrations in sampled tap waters supplied by each large water supply company in England and Wales for 2015. For scoping calculations, by assuming that the distribution of such arsenic concentrations for each water supply company was log normal, the mean, $\mu_{\mathrm{i}}$, and standard deviation, $\sigma_{\mathrm{i}}$, of the modelled log normal arsenic concentration distribution for each water supply company, i, was determined by:

$\mu_{\mathrm{i}}=\left(\mathrm{P}_{1, \mathrm{i}}+\mathrm{P}_{99, \mathrm{i}}\right) / 2$

and then

$\sigma_{\mathrm{i}}=\left(\mathrm{P}_{99, \mathrm{i}}-\mu_{\mathrm{i}}\right) / 2.3263$

where $\mathrm{P}_{1, \mathrm{i}}$ and $\mathrm{P}_{99, \mathrm{i}}$ are the 1 st and 99 th percentile respectively of the $\log$ (arsenic concentration) distribution of the subscripted water supply company, $i$, and where 2.3263 corresponds to $t_{99}$ for a normal distribution with an infinite number of degrees of freedom. As $\mathrm{t}_{99}$ for $\mathrm{df}=100$ is 2.364 , the error introduced by ignoring the finite number of tests for each water supply company with over 100 sample tests was accordingly less than $2 \%$. In 2015, water supply companies carrying out $<100$ sample tests in total supplied less than $0.2 \%$ of the total population supplied by water supply companies in the UK and overwhelmingly at arsenic concentrations lower than the overall mean supplied, so no substantive model errors arise from the use of the $t_{.99}$ figure per se.

In the absence of equivalent summary data for Scotland, for the scoping calculation, the contribution of public water supplies in Scotland to the overall UK distribution was calculated by correcting for the relative populations of Scotland and the whole UK.

\subsection{As hazard distribution - detailed method}

For a more robust calculation, more detailed data, including mean arsenic concentrations in sampled taps and population, of the approximately 1900 water supply zones in the UK was obtained directly from the 23 largest water supply companies in the UK excluding Scotland. Water quality data and water supply zone data for Scotland was obtained for 2016 from public websites as the required comprehensive data for water regulation zones for 2015 was not provided by Scottish Water. Across the UK, for the 10 individual water supply zones for which data was not available, the arsenic concentration was assumed to be the mean of the arsenic concentration supplied by the relevant water supply company. For the 5 smallest (in terms of population supplied) UK water supply companies, arsenic concentration and population supplied over the entire area of their water supply was used as published by DWI (2016).

\subsection{Water consumption rates}

Mean daily total liquid consumption for the population was taken to be $2.003 \mathrm{~L} \mathrm{day}^{-1}$ (Accent, 2008). This accounts for both water consumed directly via taps $\left(1.314 \mathrm{~L} \mathrm{day}^{-1}\right)$ and that consumed indirectly via incorporation into food and is broadly similar to that determined for the USA (Burmaster, 1998).

\subsection{Dose-response relationships for arsenic-attributable sequela at low exposures}

Reflecting the paucity of relevant epidemiological studies and focusing on perceived likely first order effects, simplified scoping calculations of populationlevel detrimental health outcomes arising from chronic exposure to arsenic in drinking water at concentrations less than $10 \mu \mathrm{g} \mathrm{L}^{-1}$, here, were restricted to (i) premature death end-points (i.e. not considering morbidity); (ii) the, arguably, most important two broad categories of sequela, cancers and cardiovascular disease, and (iii) without detailed consideration of age, gender, genetic, dietary and socio-economic confounders.

The model all-cancer annual risk, $\mathrm{R}_{\mathrm{c} \text {,annual, of }}$ mortality attributable to tap water arsenic with concentration, C, was calculated from equation (3)

$\mathrm{R}_{\mathrm{c}, \text { annual }}=\left(\mathrm{C} / \mathrm{C}_{\mathrm{ref}}\right) \mathrm{R}_{\text {ref }} / \mathrm{E}$

where $\mathrm{C}_{\text {ref }}$ is the reference concentration of arsenic, taken here to be $10 \mu \mathrm{g} \mathrm{L}^{-1}$ and for which the lifetime all-cancer risk, $\mathrm{R}_{\mathrm{ref}}$, attributable to the arsenic is taken to be 2000 per 100,000 (NRC, 2001), and $\mathrm{E}$ is the estimated mean life expectancy of the population of UK calculated from ONS (2017). Total model arsenic attributable premature deaths were then calculated by numerically integrating these risks over the distribution of tap water arsenic concentration.

We explored the use of the log-linear models reported in the meta-analysis of Moon et al. (2017) of studies of CVD mortality arising from low level arsenic exposures, however, the nature of the model precludes its robust extrapolation to concentrations much below their reference concentration of $10 \mu \mathrm{g}$ $\mathrm{L}^{-1}$, even with the adoption of a reference arsenic concentration corrected to $1 \mu \mathrm{g} \mathrm{L}^{-1}$, being a conservative (with respect to risk estimates; upper) estimate of the mean arsenic concentration supplied by UK water supply companies as well as an approximation for the volunteer-weighted mean of median references concentrations in the studies reviewed by Moon et al. 
(2017). Rather, we based our estimates of excess CVD

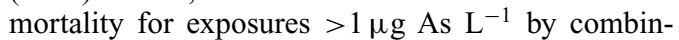
ing ONS (2017) reported overall UK CVD mortality rates with the $2.2 \%$ (CI- $0.9 \%, 5.5 \%$ ) increase in fully adjusted CVD mortality rates for those drinking water with $1-10 \mu \mathrm{g} \mathrm{As} \mathrm{L}^{-1}$ compared to a $<1 \mu \mathrm{g} \mathrm{As} \mathrm{L}^{-1}$ reference, as reported in the ecological study for Spain of Medrano et al. (2010).

\section{RESULTS AND DISCUSSION}

\subsection{As hazard distribution - scoping calculation}

Scoping calculations, assuming a log normal distribution of arsenic concentrations for each water supply company, indicated on the order of $10^{5}$ persons supplied with tap water with a $\geq 5 \mu \mathrm{g}$ As $\mathrm{L}^{-1} ; 10^{6}$ with $\geq 2 \mu \mathrm{g} \mathrm{L}^{-1}$; and $10^{7}$ with $\geq 1 \mu \mathrm{g} \mathrm{L}^{-1}$. However, although such $\log$ normal distributions have been widely found to be functional models of the distribution of chemical constituents in groundwater (e.g. Zikovsky \& Chah, 1990) substantial deviations, including from right-skewness and polymodality have been observed in many datasets (Shand et al., 2007). In this study, comparison with the more robustly calculated distribution (Fig. 1) shows that large deviations from $\log$ normality arise, in part, also because of (i) data censoring at low concentrations near method detection limits and (ii) truncation of high concentrations near the UK PCV because of the regulatory compliance by water supply companies. Here, the magnitude of the model errors as a function of concentration over the range 1 to $7 \mu \mathrm{g} \mathrm{As} \mathrm{L}^{-1}$ are on the order of $10 \mathrm{~s}$ to $100 \mathrm{~s} \%$ - although high, indicating the utility of the method, if used with caution, for scoping calculations, in the absence of more detailed data, from the limited summary water supply quality data often available in the public domain.

\subsection{As hazard distribution - detailed method}

Our more detailed analysis shows that approximately 130,000 consumers in the UK are supplied with drinking water with $\geq 5 \mu \mathrm{g} \mathrm{As} \mathrm{L}^{-1}$; the equivalent figures for other concentrations being 1,080,000 for $\geq 2 \mu \mathrm{g} \mathrm{L}^{-1}$ and 9,750,000 for $\geq 1 \mu \mathrm{g} \mathrm{L}^{-1}$ (see Fig. 1).

\subsection{Estimated arsenic attributable health risks}

Calculated model health risks are shown in Figure 2 and are of the order 100 to 1000 per annum - this is similar in magnitude to UK deaths arising from car occupants in road traffic accidents (ONS, 2017). Most of the modelled excess mortality arises from arsenic concentrations less than $5 \mu \mathrm{g} \mathrm{L}^{-1}$ with broadly similar contributions from all-cancer and CVD.

There are considerable model and parameter uncertainties inherent in these estimates (cf. Monrad et al., 2017), but nevertheless they suggest that there could be public health benefits in the UK by tightening the UK PCV for arsenic in drinking water from $10 \mu \mathrm{g}$ $\mathrm{L}^{-1}$ to a lower value (cf. Moon et al. (2017) with

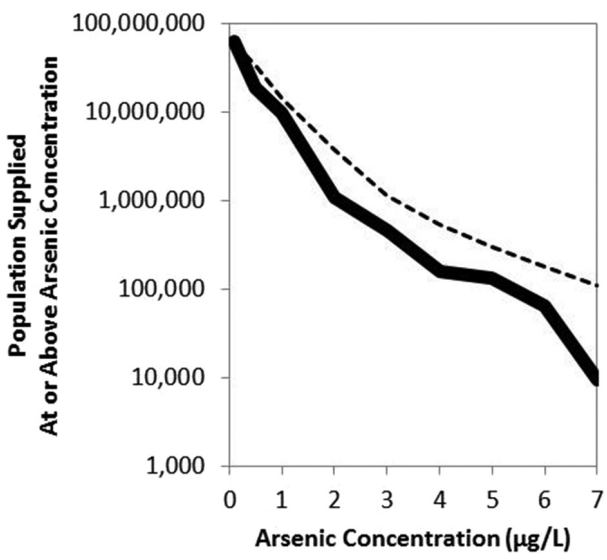

Figure 1. Cumulative distribution of arsenic hazard in UK tap water supplied by water supply companies in 2015 (includes Scotland data instead for 2016). The dashed line shows overestimated hazard distribution using limited public domain DWI (2016) summary data and calculated assuming a log normal model for waters supplied by each water supply company.

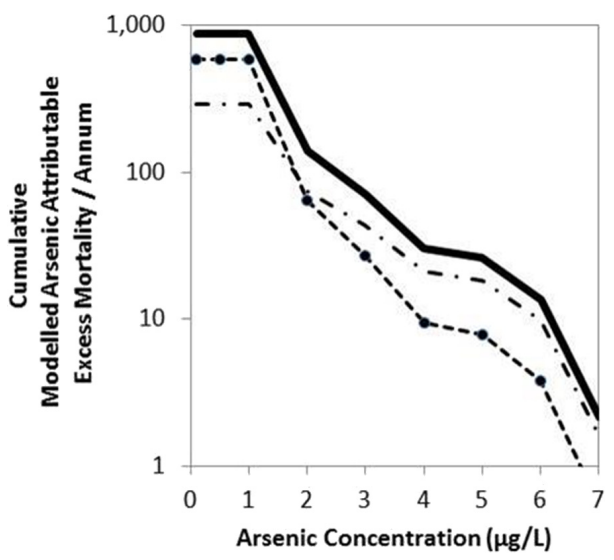

Figure 2. Modelled cumulative distribution of excess mortality per annum due to cardiovascular disease (dashes), all cancers (dot-dash) and combined (solid line). See text for limitations.

respect to the USA). This is likely to be highly relevant to many, if not most, other countries across the globe and might, of itself, help to drive innovation to find more cost-effective arsenic remediation and mitigation technologies and other instruments relevant to these hitherto considered relatively low concentrations (Polya \& Richards, 2017).

\section{CONCLUSIONS}

Although regulatory compliance of UK water supply companies with the UK PCV of $10 \mu \mathrm{g} \mathrm{L}^{-1}$ is outstanding, about 1,080,000 consumers in the UK are supplied by water supply companies with drinking water with As $\geq 2 \mu \mathrm{g} \mathrm{L}^{-1}$ giving rise to modelled 
arsenic attributable excess mortality on the order of 100 to 1000 per annum. The nature and magnitude of dose-response relationships for arsenic in drinking water at concentrations below $10 \mu \mathrm{g} \mathrm{L}^{-1}$ is currently a controversial matter - indeed some argue that the excess health risks at these concentrations are negligible - further research into the mechanisms of action and epidemiology of arsenic-attributable detrimental health outcomes at concentrations around and below the $\mathrm{WHO}$ provision guide value are indicated.

\section{ACKNOWLEDGEMENTS}

We acknowledge with thanks the data provided by the 23 largest UK (excluding Scotland) water supply companies as well as their approvals to use their data for this research published in the public interest. Any opinions expressed in this abstract are those of the authors and do not necessarily reflect those of any of these companies. Data from the UK Drinking Water Inspectorate (DWI) for England and Wales are used here under the terms of a UK Open Government License for public sector information, conditions at: $\mathrm{http} / /$ www.nationalarchives.gov.uk/doc/open-govern ment-licence/version/3/. LX acknowledges a University of Manchester President's PhD Scholarship and JL a NERC CASE (Health and Safety Executive's Health and Safety Laboratory (HSE's HSL)) PhD Studentship through the Manchester-Liverpool NERC EAO DTP. We thank Nick Warren (HSE's HSL) for statistical advice. DCG and MJA publish with the permission of the Executive Director, British Geological Survey (NERC).

\section{REFERENCES}

Accent 2008. National Tap Water Consumption Study Drinking Water Inspectorate 70/2/217 Phase Two Final Report.

Ander, E.L., Watts, M.J., Smedley, P.L., Hamilton, E.M., Close, R., Crabbe, H., Fletcher, T., Rimell, A., Studden, M. \& Leonardi, G. 2016. Variability in the chemistry of private drinking water supplies and the impact of domestic treatment systems on water quality. Environ. Geochem. Hlth. 38(6): 1313-1332.

Burmaster, D.E. 1998. Lognormal distributions for total water intake and tap water intake by pregnant and lactating women in the United States. Risk Anal. 18(2): 215-219.

Crabbe, H., Close, R., Rimell, A., Leonardi, G., Watts, M.J., Ander, E.L., Hamilton, E.M., Middleton, D.R.S., Smedley, P.L., Gregory, M., Robjohns, S., Sepai, O., Studden, M., Polya, D.A. \& Fletcher, T. 2017. Estimating the population exposed to arsenic from groundwatersourced private drinking water supplies in Cornwall, UK. In: Bhattacharya, P., Polya, D.A. \& Jovanovic. D. (eds) Best Practice Guide for the Control of Arsenic in Drinking Water, IWA Publishing, London, UK; Chapter A3, pp. $161-170$.

DWI (Drinking Water Inspectorate). 2016. Drinking water 2015 - chief inspectors' report. DWI. Available from: http://www.dwi.gov.uk/about/annualreport/2015/index .html Last updated 5 August 2016. Last accessed 2 October 2017.
García-Esquinas, E., Pollán, M., Umans, J.G., Francesconi, K.A., Goessler, W., Guallar, E., Howard, B., Farley, J., Best, L.G. \& Navas-Acien, A. 2013. Arsenic exposure and cancer mortality in a US-based prospective cohort: the strong heart study. Cancer Epidemiol. Biomarkers Prev. 22(11): 1944-1953.

Medrano, M.J., Boix, B, Pastor-Barriuso, R., Palau, M., Damián, J., Ramis, R., del Barrio, J.L. \& Navas-Acien, A. 2010. Arsenic in public water supplies and cardiovascular mortality in Spain. Environ. Res. 110(5): 448-454.

Middleton, D.R.S., Watts, M.J., Hamilton, E.M., Ander, E.L., Close, R.M., Exley, K.S., Crabbe, H., Leonardi, G.S., Fletcher, T. \& Polya, D.A. 2016. Urinary arsenic profiles reveal exposures to inorganic arsenic from private drinking water supplies in Cornwall, UK. Sci. Rep. 6: Art. 25656.

Monrad, M., Ersboll, A.K., Soresnen, M., Baastrup, R., Hansen, B., Gammelmark, A., Tjonnneland, A., Overvad, K. \& Tassschou-Nielsen, O. 2017. Low-level arsenic in drinking water and risk of indident myocardial infarction: a cohort study. Environ. Res. 154: 318-324.

Moon, K.A., Oberoi, S., Barchowsky, A., Chen, Y., Guallar, E., Nachman, K.E., Rahman, M., Sohel, N., D’Ippoliti, D., Wade, T.J., James, K.A., Farzan, S.F., Karagas, M.R., Ahasan, H. \& Navas-Acien, A. 2017. A dose-response meta-analysis of chronic arsenic exposure and incident cardiovascular disease. Int. J. Epidemiol. 46(6): 1924-1939.

NRC (National Research Council). 2001. Arsenic in Drinking Water: Update. National Academy Press, Washington, DC.

Polya, D.A. \& Middleton, D.R.S. 2017. Arsenic in drinking water: sources \& human exposure routes. In: Bhattacharya, P., Polya, D.A., Jovanovic. D. (eds) Best Practice Guide for the Control of Arsenic in Drinking Water. IWA Publishing, London, UK; Chapter 1, pp. 1-23.

Polya, D.A. \& Richards, L.A. 2017. Arsenic and the provision of safe and sustainable drinking water. Asia Pacific Tech Monitor, July-Sept 2017, 23-30, UNESCAP.

Pompili, M., Vichi, M., Dinelli, E., Erbuto, D., Pycha, R., Serafini, G., Giordano, G., Valera, P., Albanese, S., Lima, A., de Vivo, B., Cicchella, D., Rihmer, Z., Fiorillo, A., Amore, M., Girardi, P. \& Baldessarini, R.J. 2017. Arsenic: association of regional concentrations in drinking water with suicide and natural causes of death in Italy. Psychiatry Res. 249: 311-317.

Ravenscroft, P., Brammer, H., Richards, K. 2009. Arsenic Pollution. Wiley-Blackwell: London, UK.

Roh, T., Lynch, C.F., Weyer, P., Wang, K., Kelly, K.M. \& Ludewig, G. 2017. Low-level arsenic exposure from drinking water is associated with prostate cancer in Iowa. Environ. Res., 159: 338-343.

Shand, P., Edmunds, W.M., Lawrence, A.R., Smedley, P.L. $\&$ Burke, S. The natural (baseline) quality of groundwater in England and Wales. 2007. British Geological Survey Research Report RR/07/06. Environment Agency Science Group: Air, Land and Water Technical Report $\mathrm{NC} / 99 / 74 / 24$.

Smith, A.H., Lingas, E.O. \& Rahman, M. 2000. Contamination of drinking-water by arsenic in Bangladesh: a public health emergency. Bull. World Health Organ. 78(9): 1093-1103.

Zikovsky, L. \& Chah, B. 1990. The log-normal distribution of radon concentration in ground-water. Ground Water 28(5): 673-676. 